relatire absence of albuminuria, one has no difficulty in attributing them to chronic Bright's disease. They are in the stage of quiesence-the stage so often recognised of chronic renal disease without albuminuria. The absence of albumin does not remove them from the category of chronic renal trouble. I even venture to doubt whether since Bright's discorery of the association of albuminuria with renal changes the true significance of many cases has not been obssured, rather than helped, by the constant search for albumin. To take only one aspect, that of life assurance, I believe that by many medical examiners both these cases might have been passed; and I fear that in testing for albumin we may perhaps be tempted to devote too little attention to the appearance of the patient and the character of the pulse. Further, I think that the true bearings of these cases might readily be overlooked if at a ater stage they presented themselves for the treatment of dyspeptic troubles. The dimness of vision of which the man complained might easily be referred to dyspepsia, while an intermittent pulse is, according to many teachers, of so little moment that, if the primary cause of complaint appeared to be dyspepsia, the intermission might probably be resarded as a passing vagary scarcely worth noting.

From what has been said it will be seen that I consider it most important, when dealing with dyspepsia, and albuminuria, to endeavour to form an accurate idea of their relation to one another. Not only the prognosis, but also the treatment, depend largely upon a correct recognition of whether the indigestion is the result or the exciting cause. If it is the result the nature of treatment must vary somewhat with the urgency of the symptoms. In any case free purgation is essential, and the use of hydragogue purgatives is to be mreferred. We should never attempt to stimulate the action of the kidney directly by diuretics, even when the amount of arine passed is much below the normal quantity. If the mature of the urine indicates acute engorgement our object should be to promote physiological rest, to diminish the amount of work required of the kidney by removing water from the system by other channels. Frequently, in severe vases, the use of the wet pack or the vapour bath becomes an all-important factor in the treatment of renal vomiting. If Te recognise at an early stage the true renal nature, vur treatment is more likely to be serviceable than if we confine our attention to the condition of the stomach. Regulation of diet and the use of gastric sedatives, although they should not be neglected, are not likely to give good results unless at the same time we treat the anderlying cause of the symptoms. On the other hand, if the symptoms are not so urgent, and if we have reasonable cause for suspecting that the albuminuria is the result of the dyspepsia, our course is equally clear. We must endearour to ascertain whether the trouble is merely dietetic or whether it is oxaluric or lithæmic, but I will not be wearisome by-giving any further details of a subject so simple. The main thing is to regulate the diet and by careful study of the individual case to determine what constituent should be remored. Sometimes it is a mere question of distribution, preventing overloading of the stomach on one or two occavions during the day. Sometimes we find it necessary to eliminate eggs or pastry or cheese ; in oxaluric cases we remore sugar and reduce the vegetable acids, and so on. The treatment really presents no difficulty when once a satisfactory diagnosis has been made.

To stite briefly the conclusions to be drawn from the foregoing observations, although I would by no means underrate the importance of testing the urine in every case of chronic dys sepsia occurring in adult life, so as to run no risk of overlooking an existing Bright's disease, I venture to lay stress upon the frequency with which long-continued dyspepsia stads in the position of predisposing cause, rather than as the result of chronic kidney disease.

Harley-street, w.

Kent Benevolent Medical Society. - The ancual meeting of the members of the Kent Benevolent Medical Soci:ty was held last week in the library of the Kent and Canterbury Hospital. Mr. A. Long of Dover presider, and the accounts for the year showed that of f 421 13. 1d. Which had been received during the past twelve montu. (including a legacy of $£ 50$ from the late Mr. John Jarshall of Dover) a sum of $£ 371$ 14s. $1 d$. had been expented. The meeting unanimously resolved that $£ 100$ out of the balance in hand should be added to the invested capital o: the society, and that the sum of $£ 305$ should be distributed amongst the applicants whose names were before the meeting.

\section{A MODIFICATION OF DR. FOWLER'S METHOD OF STERILISING CATGUT. ${ }^{1}$}

Bx HeNRY JelLeTT, B.A., M.B., B.Ch., B.A.O. Dub., ASSISTANT MASTER, ROTUNDA HOSPITAL, DUBLIN.

THE perfect sterilisation of catgut is such an important point in modern surgery that the following method of accomplishing it may be of interest to surgeons. The mechanical details of the process are new as far as I am aware, but the principle was originated by Dr. Fowler, who sterilises catgut by sealing up suitable lengths of it in a strong horseshoeshaped glass tube containing alcohol, the tube being then raised to whatever temperature is thought advisable either by heating it in some liquid of sufficiently high boiling point or by placing it in a dry steriliser. Catgut, owing to its origin and mode of preparation, is essentially a septic material. It is made by twisting into cords the specially prepared submucosa of the small intestines of the sheep, and the twisting process has the effect of bringing bacteria, which at first were on the outside of the intestine, into the centre of the threads. The fat which is present then glues the different strands firmly together and encloses the bacteria in a sheath which is impermeable to the ordinary means of sterilisation. When, however, the catgut is introduced into the body, during the process of absorption every particle of it is layer by layer brought into contact with the surrounding tissues, so that while bacteria contained in silk or silkworm gut may never come into contact with the tissues every bacterium present in catgut is of necessity obliged to do so, and it is this property of being absorbed which makes the absolute asepsis of catgut so imperative.

The chief methods of rendering anything aseptic are(1) the removal of germs by mechanical meana, and (2) the destruction of them by germicides. The first of these is useless as far as catgut is concerned, and we must rely upon germicides, which can be divided generally into - (1) certain chemical substances and (2) heat in some form. Chemical methods are all placed at a great disadvantage owing to the bacteria in catgut being encased in fat: They mostly depend on first removing as much of the fat as possible by soaking the catgut in ether and then sub. jecting it to the prolonged action of an antiseptic, but all these methods necessitate very frequent changth of the solution, they are exceedingly expensive, and they are very far from certain, for cultivations have of ten been grown from catgut which was beliered to be absolutely pare. Heat is very much more certain in its operation than chemical antiseptics, for boiling water will destroy anthrax spores in two minutes, while even 1 per cent. solution of corrosive sublimate will require several hours for the same purpose. Boiling water or steam, however, cannot be applied to catgut, as it swells in them and becomes a shapeless mass, while dry heat is difficult to manage and requires very many precautions in its use, else the catgut becomes brittle and useless. In short, a medinm is required in which catgut can be heated without destroying its strength, and this is best furnished by alcohol, which, however, boils at $173^{\circ} \mathrm{F}$., and as this temperature is not suffeient the alcohol must be super-heated.

By Dr. Fowler's method already described the catgut is raised to $212^{\circ}$, the bacteria are destroyed, and at the same time the gut is kept strong and serviceable, but the surgeon is under the necessity of buying catgut already prepared and sterilised. I venture, therefore, to make known the following slight modification of Dr. Fowler's method, as it enables the sterilisation to be easily and quickly performed by anybody. The catgut, instead of being sealed up in glass tubes, is rolled on glass plates and placed in a special brass box three-quarters full of alcohol, and the whole is then immersed in boiling water for the necessary time. The box is strong enough to stand the required pressure-viz., a force of about four pounds to the square inch. It has a screw-top provided with an indiarubber washer and projecting arms above and below to facilitate screwing it up or opening it. The catgut must be absolutely dehydrated and must not

1 A paper read before the Obstetrical Section of the $R$ yyal Academy 1 A paper read before the Obstetrical Sed
of Medicine in Ireland on April 6th, 1896. 
be rolled too tightly on the plates. A coil of ninety inches long will lose from half an inch to an inch of its length during its preparation, so that if it is rolled too tightly at first it will be very much weakened, and also will be extremely difficult to unwind from the plates. It should be very loosely rolled on the glass plates and placed in a jar containing absolute alcohol for three or four days in order that the contained water may be perfectly remored. The plates are then transferred to the brass box, which is three-quarters filled with alcohol, and after screwing on the lid it is placed in a saucepan in cold water and boiled over a stove, being removed a quarter of an hour after the water has begun to boil. The water in the saucepan should at first be cold, or nearly so, because when it begins to boil the brass box and its contents have reached the same temperature as the water and, therefore, the catgut is kept for fifteen minutes at $212^{2}$; but if the water were boiling at the commencement some little time would be required for the heating of the box and its contents, and the catgut might not be kept long enough at the required temperature. When the box has cooled the plates are removed to a jar filled with a mixture of alcohol and glycerine, containing from 5 to 20 per cent. of glycerine according to the degree of stiffness required in the catgut. This mixture of alcohol and glycerine should be changed every week or ten days, for alcohol has an extremely small germicidal action and bacteria fall into the jar during the removal of pieces of the catgut from the plate.

Whilst the primary object of this steriliser is to prepare catgut it can be used for sterilising by heat anything which cannot be placed in boiling water, such, for example, as sea-tangle tents. It can also be used to re-sterilise the mixture of alcohol and glycerine in which the gut is kept. The steriliser is made by Messrs. Fannin and Co., Graftonstreet, Dublin.

\section{Clinitad a thotes:}

\section{MEDICAL, SURGICAL, OBSTETRICAL, AND THERAPEUTICAL.}

\section{"TRANSIENT AMBLYOPIA DURING LACTATION."}

By Chaples E. S. Flemming, M.R.C.S. ENG., L.R.C.P. LOND.

IN I'HE LANCET of July 18th there is an annotation with the above heading, and as these cases are not common I venture to send notes of a case which lately occurred in my practice.

A healthy woman aged forty-two years was confined on the morning of April 10th, 1896. The labour was normal and she seemed to be doing well until the morning of the 13th, when she became almost blind, had marked photophobia, and severe frontal headache. Her pulse was full and her temperature was $100^{\circ} \mathrm{F}$. The bowels had acted freely during the night. The next day the temperature was $99.2^{\circ}$, but the headache and photophobia continued as severe and she had merely perception of light. I thought I detected some swelling of the disc, but it was not marked and there was much difficulty in examining the eye. There were no other signs then or later of septic mischief, and on the following day the temperature was normal. On the fourth day the pain began to subside and vision improved a little, but it was a fortnight before the headache and photophobia quite disappeared, and then, although vision had much improved, the patient described it as much worse than it used to be. She informed me that she had had "weak" sight since childhood, and that her left eye had always squinted, and that she had never been able to see more than light with it. After each of the two previous confinements she suffered in the same way from pain and blindness only in a less degree. Her health had otherwise always been good. Six weeks later I examined her eyes under atropine and found: left internal strabismus fixed; right disc normal, left small; mixed astigmatism in both eyes; right vision $=\frac{B}{6}$ with correction $\frac{g}{i}$, and left vision $=$ perception of light.

Freisford, Iath

\section{ACEPHALOUS INFANTS.}

BY J. L. KERR, M.D., C.M. ABERD., F.R.S.E. LATE EXAMINER IN CHEMISTRY AND IN MEDICAL JURISPRUDEXCE, UNIVERSITY OF ABIEDEEN.

I HAVE lately attended two women who gave birth to acephalous infants. One was a young woman and the other a middle-aged woman. In each case the child was of rery large proportions and otherwise of normal conformation and very well nourished; both would have been living if the parturition had been easy and uncomplicated. The portion of the skull which was absent was in each case occipito parietal, an oblique line passing downwards and backwards from above the middle of the forehead above the ears to the occipital protuberance being the boundary. The conclusion come to by me from inspection of the parts is that each was a case of intra-uterine amputation, the same as is seen in children born without a portion of some limb. Any further observations by others may confirm or correct my theory and are hereby solicited.

Crawshawbooth, Manchester.

\section{AXILLARY VERSUS RECTAL SALINE INJECIIONS}

\section{By George Henry BuTlen, L.R.C.P. Irex,, L.R.C.S.EDIX}

THE case of injection of normal saline fluid into the axilla for severe loss of blood lately recorded in THE LANCET leads me to think that a report of the following case, which occurred in my practice recently, may be of interest to some of my fellow practitioners.

On June 29th last, about 2 P.M., I received an urgent message to visit a woman. On my arrival I found her in bed, blanched from loss of blood, the pulse imperceptible, respiration sighing, and nearly constant vomiting. In fact, the symptoms and appearances were those of impending death from bæmorrhage. I found she had gone nearly ber full term in pregnancy and had been losing blood very freelp for some hours. There had also been slight loss of blood at intervals for about a month past. It being impossible to give nourishment or stimulants by the mouth on account of the constant sickness I injected strychnine and brandy hypodermically, and as soon as the patient had rallied somewhat proceeded to make an examination. The pains were very slight. I could feel the edge of the placenta tbrough the os, which was dilated just sufficiently to pass a finger, and separated it from the uterine wall as far as I could reach. The membranes could not be reached. I then plugged the os and vagina thoroughly with wool gauze and injected ergotinine. The patient at this stage and for about two hours was in a desperate condition, and I resorted twice to the injection of normal saline fluid into the rectum with extremely good results. It was necessary to press a pad firmly against the anus in order to retain them, on account of the violent retching at frequent intervals. After waiting three hours, and having injected ergotinine again, the pains being stronger, I removed the plug in hopes of being able to rupture the membranes. I found the os very little larger and bleeding coming on very freely I plugged again. The patient having somewhat improved, I left her at 6.30. On visiting her again at 8.30 I found her better, the pains much stronger and more frequent. There had been no further loss. I now removed the plug and found the os dilated to the size of half-a-crown. The presentation was cranial, first position, and I was now able to rupture the membranes. At the patient's urgent request I gave a little chloroform and in about an hour delivery $\$ 2 s$ effected by the natural powers. The child was stillborn. The woman has made a good recovery. I think this mode of introducing saline fluid into the system is quite as effectail and much less painful than the other. I had no apparatis for transfusion with me. The case was much handicappet by the sickness. No nourishment could be retained till aitter delivery was effected; only small pieces of ice sucked fre quently. I cannot help thinking that the woman's life wonit have been lost had any violent measures for effecting immediate delivery been resorted to. The only chare seemed to be to stop the loss and give her time to rally.

Wealdstone, Middlesex. 